\title{
Effect of Growing Media on Rhizogenesis and Growth of Rooted Stem Cuttings of Pomegranate (Punica granatum) cv. Phule Bhagwa Super. Under Open Field Condition
}

\author{
Mohammad Ghani*, M.K. Sharma and Hukum Khan Habibi
}

Department of Horticulture, S.K.N College of Agriculture, Jobner, Jaipur, Rajasthan, India

\author{
A B S T R A C T
}

\begin{tabular}{|c|}
\hline Keywords \\
\hline $\begin{array}{l}P \text {. granatum L. } \\
\text { Cuttings, Sand, } \\
\text { Soil, FYM, } \\
\text { Cocopeat, } \\
\text { Vermiculite, Perlite }\end{array}$ \\
\hline Article Info \\
\hline $\begin{array}{l}\text { Accepted: } \\
10 \text { June } 2019 \\
\text { Available Online: } \\
10 \text { July } 2019\end{array}$ \\
\hline
\end{tabular}

The investigation conducted at Fruit Nursery Block, Department of Horticulture, S.K.N. College of Agriculture, Jobner (Jaipur) Rajasthan during February 2018 to July 2018 entitled "Effect of Growing Media on Rhizogenesis and Growth of Rooted Stem Cuttings of Pomegranate (Punica granatum L.) cv. Phule Bhagwa Super" under open field condition. The experiment comprising different type of media and their combination viz. Sand , Sand +FYM, Sand + Cocopeat, Sand +Perlite, Sand +Vermiculite , Sand +Soil+ FYM, Sand + Soil+ Cocopeat, T8Sand + Soil + Perlitet, Sand +Soil + Vermiculite. To evaluate the effect of different type of media on rhizogenesis and growth of rooted stem cuttings of pomegranate. Result revealed that maximum number of root (8.66) and number of leaves (24.56) at 120 DAP were recorded in T7 (sand +soil + cocopeat). While length of primary shoot (27.14), length of primary root (28.43) survival percentage $(60.00 \%)$ benefit: cost ratio (8.30) at 120 DAP, Days taken to start sprouting (17.66) and days taken to $50 \%$ sprouting (19.96) were recorded in T6 treatment combination of sand+ soil+FYM. Therefor it may be concluded and that the $P$. granatum L. cuttings planted in sand + soil+ FYM (1:1:1) was found to be best suitable media for pomegranate vegetative propagation.

\section{Introduction}

Pomegranate (Punica granatum L.) is a deciduous shrub or small tree belongs to the family Punicaceae grown as semi-arid fruit crop.

It is considered to have been originated in Iran and Afghanistan and under cultivation since ancient time. In old Latin, the name Malumpunicum literally translates to "Apple of Grain" or "multi-grain", with reference to the multiple seeds in the fruit. However, the current Latin name Punica granatum L. is derived from "Pomunigranatum" a name traced back to the middle ages, which translates to "seeded apple". It is extensively cultivated in Spain, Morocco and other countries around the Mediterranean, Egypt, Iran, Afghanistan, Arabia and Baluchistan.

It has $2 \mathrm{n}=2 \mathrm{x}=16,18$ chromosomes (Smith, 1976). Pomegranate has different ecotypes viz., cultivated (Punica granatum L.), wild 
types (Punica protopunica) and ornamental forms (Japanese Dwarf pomegranate - Punica granatum var. Nana). In India, it is cultivated over 2.16 lakh ha with a production of 27.95 lakh tones and productivity of 12.94 tones/ha (Anonymous, 2016-17a).The best quality pomegranate fruits are produced in regions with cool winters and hot dry summers. The pomegranate tree has great adaptability to adverse climatic conditions. It can withstand severe colds, salinity and tolerate drought thereby growing very well in semi-arid zones. The tree is quite resistant to cold when it is dormant and can withstand temperature upto $10^{\circ} \mathrm{F}$. However, it is very sensitive to frost before it reaches full dormancy in late fall and after that buds have begun to swell in early spring.

Pomegranate can be propagated by stem cutting, layering, bottom sprouts and grafting. However, pomegranate is commercially propagated by one year old stem cuttings under mist propagation or by air layering.

Vegetative propagation in pomegranate is of utmost importance to propagate true to type plants. Through air layering is successful in pomegranate but it is expensive, cumbersome and it adversely affects the growth of the mother trees. Propagation of pomegranate by cuttings is the most convenient and cheapest method to obtain fully developed and stronger trees with in less time. Some factors that affect the rooting of pomegranate cuttings are physiological condition of the parent plant, cutting type, season of cutting, rooting medium and use of rooting hormones (Polat and Caliskan, 2009). Rooting medium plays an important role in rooting of cuttings and for further growth and development of cuttings. The medium should be sufficiently firm and dense to hold the cuttings in place during propagation. It also provides moisture and air to the base of cutting. Suitable medium for cutting establishment should have enough moisture and good aeration. Use of optimum rooting media and optimum environmental conditions play a vital role in rapid multiplication of pomegranate cuttings.

In order to reduce the high mortality of rooted cuttings under field conditions, it is highly desirable to build a healthy and well developed root system to enabling better field establishment of pomegranate trees by growing in suitable medium and providing favourable environmental conditions. So far, research work done on propagation of pomegranate through cuttings using different rooting media under variable environmental conditions is very meagre.

Rooting media is one of most important factors for better rooting of cuttings and survival of the rooted plants. There are different media like soil, sand, perlite, vermiculite, FYM Peat, Sphagnum moss, Leaf mould, saw dust, shredded bark, Pumice, Perlite, and rice straw, which play important role in success of rooting of cuttings. Some media have higher moisture holding capacity with lighter weight, which enhance root formation. So rooting of cutting can be significantly increased with the use of different media. The nurserymen and propagators use different kinds of media for the propagation of different horticultural plants consisting of a mixture of organic and inorganic compounds that have different but complementary properties. Nurserymen propagate and perpetuate horticultural plants through seed, cuttings or other methods of propagation. The appropriate propagation medium depends on the species; propagule type, seasons, propagation system cost and availability of the medium are the components for the choice of the medium.

\section{Materials and Methods}

The present investigation entitled "Effect of Growing Media Rhizogenesis and Growth of Rooted Stem Cuttings of Pomegranate 
(Punica granatumL.) cv. PhuleBhagwa Super" conducted at Fruit Nursery Block, Department of Horticulture, S.K.N. College of Agriculture, Jobner (Jaipur) during February 2018 to July 2018. The detail of techniques followed and the material used during the course of investigation are described under suitable heads:

The semi hardwood stem cuttings of uniform size $(15-20 \mathrm{~cm}$ long and 0.75 to $1.00 \mathrm{~cm}$ in diameter) having 5-6 functional buds obtained in February month from well-established healthy plants of pomegranate cv. PhuleBhagwa Super from Center of Excellence for Anar, Dindhol, Bassi, Jaipur, Department of Agriculture, Government of Rajasthan. The cuttings were planted in black coloured poly bags of 7"x 7" size filed with different kinds of media and were grown under open field conditions. The experiment was laid out in a Complete Randomized Design (CRD) with three replication and ten treatments. The experiment involved planting of cutting in open field condition. The number of cuttings per treatment were 15 , thus total 150 cuttings were planted for ten treatments. Each cutting was tagged in a single treatment for recording the observations. The all planted cuttings basal end were given the treatment with Seradix powder after wetting with water.

\section{Results and Discussion}

With respect days taken to start sprouting the perusal of data in Table 1 indicated that the effect of rooting media and their combinations significantly influenced the number of days taken to start sprouting, the minimum days taken to start sprouting and days taken to $50 \%$ sprouting (17.66) and (19.96) respectively were recorded inT6 treatment combination of sand + soil + FYM. This result is in close conformity with the earlier finding by Kumar et al., (2015) and Rani et al., (2015) reported that the combination of perlite+ sand + FYM planting media resulted in minimum days taken to sprouting of cuttings in guava and (Citrus limon Burn) cv Pant lemon-1.In case of success percentage the data presented in Table 1 clearly indicated the significant effect of rooting media on success percentage of cuttings. However the data indicated, that the maximum success percentage $(93.33 \%)$. was achieved in $\mathrm{T}_{7}$ which is at par with other treatments except T9 and control. (This may be attributed to the fact that increased level of auxins resulted in earlier completion of physiological process in rooting and sprouting of cuttings these result are in close in conformity with result given by Kumar et al., (2015) in Pant Lemon -1.The perusal of data in Table 1 revealed that decreasing trends with respect to survival percentage of the cuttings was observed with the advancement of the time period i.e. 30, 60, 90 and 120 days. The maximum survival percentage was observed in T6 treatment combinations of Sand +Soil + FYM. This results is in close consonance with the earlier result given by Singh et al., (2015) and Kumar et al., (2015) in guava and (Citrus limon Burn) cv. Pant lemon -1 respectively.

The perusal of data in Table 2 further revealed that the increasing trend was observed with respect to number of shoots at an interval 30 , 60,90 and 120 days. The maximum number of shoots 3.70, 3.75, 6.80 and 7.20 were observed in T5 treatment combination of Sand + Vermiculite respectively. This result regarding total number of shoots in the present study are supported by the result obtained by Kumar, et al., (2015) who obtained highest number of shoot in 800 ppm IBA+ garden soil+ sand+ vermicompost in Citrus limon cv Pant Lemon 1. Rajkumar et al., (2017) also reported that the ratio of perlite and vermiculite provided clean, well-drained media which is favourable for better shoot and root development in pomegranate cuttings. The finding one in line with the results Bethke 
(2007) where he reported that vermiculite is having high nutrient holding capacity than perlite and contributes Potassium and Magnesium to the media which resulted in more number of shoots. With the respect to the length of primary shoot the data presented in the experimental results clearly indicated the significant effect of the rooting media on length of primary shoot in the cuttings. Significant incremental trend in the length of primary shoot was observed at periodical interval of 30, 60, 90 and 120 days after planting. The maximum length of primary shoot 7.66, 18.30, 22.73 and (27.14) at 120 DAP was observed inT $_{6}$ treatment combination of Sand + Soil+ Cocopeat. These finding regarding length of primary shoot are in consonance with the reports of Singh et al., (2015. in Citrus limon cv Pant Lemon 1. The data presented in the experimental results clearly indicated the significant effect of the rooting media on number of leaves per shoot. Significant trend in the increase of number of leaves per shoot was observed at periodical interval of 30, 60, 90 and 120 days after planting. The maximum number of leaves per shoot 7.66, 18.30, 22.73, 24.56 was observed in $_{7}$ treatment combination of sand + soil+ cocopeat. This finding is in close conformity with the earlier result given by Kumar et al., (2015) in citrus limon and Rathwa et al., (2017) in cv. Bhagwaalso reported that highest number of leaves was achieved in red Soil+ vermicompost combination of growing media in the pomegranate cuttings.

The perusal of data in Table 1 showed that significant influence in chlorophyll content in leaves and leaves area were observed due to different type of rooting media., However the maximum chlorophyll content $(2.30 \mathrm{mg} / \mathrm{g})$ was recorded in treatment $\mathrm{T}_{3}$ which was significantly superior over rest of the treatments except $\mathrm{T}_{2}$ (1.96), $\mathrm{T}_{8}$ (1.93), $\mathrm{T}_{7}$ (1.70), $\mathrm{T}_{5}$ (1.66) and maximum leaf area (3.66 $\mathrm{cm}^{2}$ ) was recorded in treatment $T_{3}$ which was significantly superior over rest of the treatments except $\mathrm{T}_{6}\left(3.13 \mathrm{~cm}^{2}\right)$ and $\mathrm{T}_{9}(2.86$ $\mathrm{cm}^{2}$ ) which is statistically at par. Finding of present investigation are in conformity with the result given by Sohnika et al., (2015). Who also reported that vermiculite + sand+ FYM treatment combination was best in the terms of the maximum chlorophyll content in the leaves of the guava cutting. In case of root parameter the data presented in Table 2 in the experimental results clearly indicated the significant effect of the rooting media on number of roots. However the maximum number of roots (8.66) was observed in $T_{7}$ treatment combination Sand + Soil+ Cocopeat. The present finding regarding number of roots are in consonance with the report of Singh et al., (2015). It might be due to release of sufficient nutrients and good aeration in the root zone of the cuttings. Ansari (2013) also reported that the mixture of vermiculite with sand was better giving higher rooting percentage and number of roots in pomegranate cuttings due to more water holding capacity and release of nutrient gradually from vermiculite. The maximum length of primary root (28.43) was observed in $\mathrm{T}_{6}$ treatment combination of sand +soil+ cocopeat.

This result is similar with the finding of Sweth (2005) who also reported that longer roots was obtained in Cocopeat substance as a compared to soil in Indian lavender, similarly Singh et al., (2015) and Kumar et al., (2015) also reported the same findings in lemon cv. Pant Lemon-1 and observed longest primary root in garden soil+ sand + vermicopost treatment combination. Sohnika et al., (2015) and Rajkumar et al., (2015) also reported that the maximum root length was measured in perlite + cocopeat combination in the pomegranate cuttings. Data presented in Table 2 further revealed that the different type of rooting media significantly influenced diameter of roots in stem cutting (Table 3 ). 
Table.1 Effect of growing media on chlorophyll content, leaf area, days taken to start sprouting, Days taken to 50\% sprouting and Success percentage of cuttings after one month in pomegranate cuttings under open field condition

\begin{tabular}{|c|c|c|c|c|c|c|}
\hline Treatment & $\begin{array}{c}\text { Chlorophyll } \\
\text { content } \\
(\mathrm{mg} / \mathrm{g})\end{array}$ & $\begin{array}{l}\text { Leaf } \\
\text { area } \\
\left(\mathrm{cm}^{2}\right)\end{array}$ & $\begin{array}{l}\text { Days taken } \\
\text { to start } \\
\text { sprouting }\end{array}$ & $\begin{array}{l}\text { Days taken } \\
\text { to } 50 \% \\
\text { sprouting }\end{array}$ & $\begin{array}{l}\text { Success percentage } \\
\text { of cuttings after } \\
\text { one month }\end{array}$ & $\begin{array}{l}\text { Benefit : } \\
\text { Cost ratio }\end{array}$ \\
\hline $\mathbf{T}_{1}$ - Sand & 1.17 & 2.13 & 19.66 & 23.83 & 86.66 & 5.79 \\
\hline$T_{2}-$ Sand + FYM (1:1) & 1.96 & 2.36 & 20.00 & 23.94 & 80.00 & 8.30 \\
\hline$T_{3}-$ Sand + Cocopeat $(1: 1)$ & 2.30 & 3.66 & 22.25 & 23.68 & 86.66 & 3.06 \\
\hline$T_{4}-$ Sand + Perlite (1:1) & 0.94 & 2.48 & 22.25 & 22.75 & 86.66 & 0.56 \\
\hline$T_{5}-$ Sand + Vermiculite (1:1) & 1.66 & 2.18 & 22.25 & 23.83 & 83.33 & 1.02 \\
\hline T $_{6}-$ Sand + Soil + FYM (1:1:1) & 1.54 & 3.13 & 17.66 & 19.96 & 86.66 & 8.30 \\
\hline$T_{7}-$ Sand + Soil+ Cocopeat $(1: 1: 1)$ & 1.70 & 2.43 & 24.76 & 24.98 & 93.33 & 6.46 \\
\hline$T_{8}-$ Sand + Soil + Perlite $(1: 1: 1)$ & 1.93 & 2.43 & 23.16 & 25.13 & 80.00 & 5.54 \\
\hline $\begin{array}{l}\text { T9- Sand }_{(1: 1: 1)} \text { Soil + Vermiculite } \\
(1: 1: 1)\end{array}$ & 1.26 & 2.86 & 22.55 & 23.33 & 73.33 & 7.39 \\
\hline $\mathbf{T}_{10^{-}}$Control (soil) & 0.70 & 1.54 & 24.40 & 25.33 & 83.33 & 5.07 \\
\hline SEm \pm & 0.24 & 0.37 & 0.61 & 0.73 & 2.98 & - \\
\hline $\mathrm{CD}(\mathrm{p}=\mathbf{0 . 0 5})$ & 0.70 & 1.09 & 2.01 & 1.72 & 8.85 & - \\
\hline
\end{tabular}


Table.2 Effect of growing media on survival percentage, number shoots, length of primary shoot and number of leaves per shoot in pomegranate cuttings under open field condition

\begin{tabular}{|c|c|c|c|c|c|c|c|c|c|c|c|c|c|c|c|c|}
\hline \multirow{3}{*}{ 氖 } & \multicolumn{4}{|c|}{ Survival percentage } & \multicolumn{4}{|c|}{ Length of primary shoot $(\mathrm{cm})$} & \multicolumn{4}{|c|}{ Number of shoots } & \multicolumn{4}{|c|}{ Number of leaves per shoot } \\
\hline & \multicolumn{4}{|c|}{ Periodical interval } & \multicolumn{4}{|c|}{ Periodical interval } & \multicolumn{4}{|c|}{ Periodical interval } & \multicolumn{4}{|c|}{ Periodical interval } \\
\hline & $\begin{array}{c}\text { 30 } \\
\text { DAP }\end{array}$ & $\begin{array}{c}60 \\
\text { DAP }\end{array}$ & $\begin{array}{c}90 \\
\text { DAP }\end{array}$ & $\begin{array}{l}120 \\
\text { DAP }\end{array}$ & $\begin{array}{c}30 \\
\text { DAP }\end{array}$ & $\begin{array}{c}\text { 60 } \\
\text { DAP }\end{array}$ & $\begin{array}{c}90 \\
\text { DAP }\end{array}$ & $\begin{array}{l}120 \\
\text { DAP }\end{array}$ & $\begin{array}{c}\text { 30 } \\
\text { DAP }\end{array}$ & $\begin{array}{c}\text { 60 } \\
\text { DAP }\end{array}$ & $\begin{array}{c}90 \\
\text { DAP }\end{array}$ & $\begin{array}{l}120 \\
\text { DAP }\end{array}$ & $\begin{array}{c}30 \\
\text { DAP }\end{array}$ & $\begin{array}{c}60 \\
\text { DAP }\end{array}$ & $\begin{array}{c}90 \\
\text { DAP }\end{array}$ & $\begin{array}{c}120 \\
\text { DAP }\end{array}$ \\
\hline $\mathbf{T}_{1}$ & 80.00 & 73.33 & 53.33 & 53.33 & 5.30 & 11.16 & 17.97 & 23.36 & 2.50 & 2.79 & 5.83 & 6.00 & 7.03 & 15.29 & 19.50 & 20.36 \\
\hline $\mathbf{T}_{2}$ & 80.00 & 73.33 & 40.00 & 40.00 & 5.77 & 11.51 & 17.25 & 23.96 & 2.83 & 2.90 & 5.50 & 5.66 & 6.30 & 14.62 & 20.16 & 23.60 \\
\hline $\mathbf{T}_{3}$ & 86.66 & 80.00 & 73.33 & 60.00 & 5.73 & 11.36 & 17.66 & 26.46 & 2.60 & 3.30 & 5.70 & 6.19 & 7.16 & 15.40 & 21.33 & 22.66 \\
\hline $\mathbf{T}_{4}$ & 73.33 & 60.00 & 33.33 & 33.33 & 5.23 & 12.52 & 19.05 & 23.33 & 2.60 & 2.99 & 5.83 & 6.03 & 6.30 & 15.67 & 19.33 & 22.16 \\
\hline $\mathbf{T}_{5}$ & 83.33 & 73.33 & 60.00 & 53.33 & 5.73 & 11.66 & 16.86 & 24.31 & 3.70 & 3.75 & 6.80 & 7.20 & 7.43 & 16.16 & 19.08 & 22.16 \\
\hline $\mathbf{T}_{6}$ & 86.66 & 86.66 & 80.00 & 60.00 & 5.93 & 10.43 & 16.71 & 27.14 & 2.66 & 2.80 & 6.66 & 5.80 & 6.26 & 15.29 & 22.55 & 22.55 \\
\hline $\mathbf{T}_{7}$ & 86.66 & 66.66 & 46.66 & 46.66 & 6.67 & 13.30 & 19.70 & 27.14 & 2.90 & 3.11 & 5.55 & 5.91 & 7.66 & 18.30 & 22.73 & 24.56 \\
\hline $\mathbf{T}_{8}$ & 73.33 & 60.00 & 40.00 & 40.00 & 5.66 & 11.12 & 19.11 & 26.18 & 2.83 & 2.96 & 5.44 & 5.94 & 6.86 & 14.91 & 16.76 & 23.36 \\
\hline $\mathbf{T}_{9}$ & 73.33 & 60.00 & 53.33 & 53.33 & 5.30 & 10.12 & 16.73 & 23.16 & 2.71 & 2.96 & 5.27 & 5.98 & 6.53 & 15.66 & 20.33 & 23.42 \\
\hline $\mathbf{T}_{10}$ & 73.33 & 76.66 & 46.66 & 46.66 & 5.00 & 11.10 & 15.90 & 23.58 & 2.60 & 2.63 & 5.55 & 5.80 & 5.94 & 14.95 & 18.16 & 20.73 \\
\hline SEm \pm & 3.49 & 3.65 & 4.08 & 3.65 & 0.10 & 0.39 & 0.59 & 0.87 & 0.11 & 0.18 & 0.21 & 0.15 & 0.15 & 0.41 & 1.02 & 0.48 \\
\hline CD & 10.38 & 10.77 & 12.04 & 10.77 & 0.61 & 1.16 & 1.75 & 2.56 & 0.34 & 0.56 & 0.63 & 0.64 & 0.64 & 1.22 & 3.00 & 1.43 \\
\hline
\end{tabular}

$\mathrm{CD}(\mathrm{p}=0.05)$

$\mathrm{T}_{1^{-}}$Sand, $\mathrm{T}_{2^{-}}$Sand + FYM (1:1), $\mathrm{T}_{3^{-}}$Sand + Cocopeat (1:1), $\mathrm{T}_{4^{-}}$Sand + Perlite (1:1), $\mathrm{T}_{5^{-}}$Sand + Vermiculite $(1: 1), \mathrm{T}_{6^{-}}$Sand + Soil + FYM (1:1:1), $\mathrm{T}_{7^{-}}$Sand + Soil+ Cocopeat $(1: 1: 1), \mathrm{T}_{8^{-}}$Sand + Soil + Perlite $(1: 1: 1), \mathrm{T}_{9^{-}}$Sand + Soil + Vermiculite $(1: 1: 1), \mathrm{T}_{10^{-}}$Control (soil) 
Table.3 Effect of growing media on number of roots, diameter of root and length of primary root in pomegranate cuttings under open field condition

\begin{tabular}{|c|c|c|c|c|c|c|}
\hline Treatment & $\begin{array}{l}\text { Number of } \\
\text { roots }\end{array}$ & $\begin{array}{c}\text { Diameter of } \\
\text { primary } \\
\operatorname{root}(\mathbf{m m})\end{array}$ & $\begin{array}{l}\text { Length of } \\
\text { primary } \\
\operatorname{root}(\mathrm{cm})\end{array}$ & $\begin{array}{c}\text { Fresh } \\
\text { weight of } \\
\text { Root (g) }\end{array}$ & $\begin{array}{c}\text { Dry weigh } \\
\text { of } \\
\operatorname{root}(\mathrm{g})\end{array}$ & $\begin{array}{c}\text { Dry matter } \\
\text { content of } \\
\text { root }(\%)\end{array}$ \\
\hline $\mathbf{T}_{1}$ - Sand & 7.00 & 1.81 & 23.66 & 2.46 & 1.17 & 47.48 \\
\hline$T_{2}-$ Sand + FYM (1:1) & 7.33 & 1.58 & 22.00 & 2.46 & 1.24 & 50.24 \\
\hline$T_{3}-$ Sand + Cocopeat $(1: 1)$ & 7.00 & 2.15 & 26.50 & 2.51 & 1.28 & 51.20 \\
\hline$T_{4}-$ Sand + Perlite (1:1) & 5.66 & 1.25 & 19.50 & 3.00 & 1.34 & 45.25 \\
\hline$T_{5}-$ Sand + Vermiculite $(1: 1)$ & 8.33 & 2.91 & 24.26 & 4.30 & 1.95 & 45.59 \\
\hline T $_{6}-$ Sand + Soil + FYM (1:1:1) & 7.00 & 2.08 & 28.43 & 3.23 & 1.90 & 58.09 \\
\hline $\begin{array}{l}T_{7^{-}} \text {Sand + Soil+ Cocopeat } \\
(1: 1: 1)\end{array}$ & 8.66 & 2.91 & 28.43 & 2.43 & 1.22 & 50.50 \\
\hline$T_{8}-$ Sand + Soil + Perlite $(1: 1: 1)$ & 6.00 & 1.50 & 23.23 & 3.16 & 1.66 & 52.16 \\
\hline $\begin{array}{l}\text { T9- Sand + Soil + Vermiculite } \\
(1: 1: 1)\end{array}$ & 6.66 & 1.33 & 22.16 & 2.56 & 1.34 & 53.94 \\
\hline $\mathbf{T}_{10^{-}}$Control (soil) & 5.33 & 1.25 & 19.93 & 2.13 & 0.97 & 45.83 \\
\hline SEm \pm & 0.42 & 0.28 & 1.37 & 0.33 & 0.17 & 3.5 \\
\hline $\mathrm{CD}(\mathrm{p}=\mathbf{0 . 0 5})$ & 1.20 & 0.68 & 4.05 & 0.99 & 0.51 & NS \\
\hline
\end{tabular}


However the maximum diameter of root $(2.91 \mathrm{~mm})$ was recorded in $\mathrm{T}_{5}$ and $\mathrm{T}_{7}$ which are significantly superior over rest of the treatments. While the minimum root diameter was recorded in $\mathrm{T} 4(1.25 \mathrm{~mm})$ which is statistically at par with the control. This finding are in close conformity with the result of Singh et al., (2015) who obtained minimum thickness of primary root in treatment combination sand +soil+ FYM in Lemon cv. Pant Lemone-1.

How evere, data clearly indicate that the maximum fresh weight of roots $(4.30 \mathrm{gm})$ was recorded in $T_{5}$ which is significantly superior over the rest of the treatments. These results with respect maximum fresh weight in the present study are in consonance with the report of Singh et al., (2015) and Rajkumar et al., (2015). They also achieved maximum fresh root weight in Perlite + Cocopeat mixture in Pant Lemon -1 and pomegranate cuttings respectively. It may attribute due to fact of the supply of sufficient quantity of nutrients and good aeration in the root zone of the cuttings of pomegranate Ansari (2013).

Different type of rooting media significantly influenced dry weight of roots. However the maximum dry weight was recorded in $\mathrm{T}_{5}$ and T6 which are significantly superior over rest of the treatments. The finding regarding fresh weight of roots are in consonance with the report of Singh et al., (2015) and Rajkumar et al., (2015) who also achieved maximum fresh root weight in Perlite + cocopeat combination of planting media followed by vermiculite+ cocopeat. Similar results are also reported by Isfendiyaroglu et al., (2009) who pointed out that sand + perlite gave highest fresh and dry weight of root in olive cuttings which might be that fact that the congenial environment in the root zone resulted in better growth of the roots and good water holding capacity and porosity of perlite also played as vital role in the growth and development of the root in the stem cuttings.
The data presented on dry matter content of roots in the experimental results indicated nonsignificant effect of rooting media on dry matter content of roots. Although the maximum dry matter of roots $(58.09 \%)$ was recorded in $\mathrm{T}_{6}$ treatment combination (sand +soil+ FYM). While the minimum dry matter content $(45.25 \%)$ was recorded in $T_{4}$ treatment combination of sand + perlite. And maximum benefit: Cost ratio (8.3) recorded in T6.

It is concluded in present investigation different type of media were applied for rooting of cutting of pomegranate cv Phule Bhagwa Super. In this regard ten treatment were tried out of ten T6 treatment combination of sand + soil+ FYM for survival percentage, Benefit:Cost ratio, days taken to start sprouting, days taken to $50 \%$ sprouting, dry matter content compared to another treatment

\section{References}

Singh, V.P., Misra, D.S., Mishra, N.K. and Rai, R. 2015. Effect of growing season, PGR and rooting media on survival of hard wood stem cut tings of lemon (Citrus limon burm.) cv. pant lemon1.Hort Flora Research Spectrum, 4(4): 347-350.

Jagdish, C.K and Vinod, K.B. 2017. Rooting of Olive cuttings cv. Pendolino and Frontoio in relation to Olea europaea the propagation medium. Advance Pharmaceutical Journal, 2(2): 69-73.

Kumar, V., Singh, M.K., Kumar, M., Parkash, S., Kumar, A. and Rao, S. 2015. Effect of different dose of IBA and rooting media on rooting of stem cutting of lemon (Citrus lemon burm) cv. Pant Lemon-1. Journal of Plant Development Science, 7(7): 587-591

Rajkumar., Gora, J.S., Kumar, R., Singh A., Kumar, A. and Gajender. 2017. Effect of different growing media on the 
rooting of pomegranate (Punica granatum L.). Journal of Applied and Natural Science, 9(2):715-719.

Rani, S., Sharma, A., Wali, V.K. Parshantbakshi and Mohdillyas, K. 2015. Standardization of best soil media and time of guava propagation through cuttings under jammu sub tropics. The Bioscan an international quality journal of life sciences, 10(3): 991-1001.

Manila, Tanuja, Rana, D.K. and Naithani, D.C. 2017.Effect of different growing media on vegetative growth and rooting in pomegranate (Punica granatum L.) cv. "Kandhari" hardwood stem cutting under mist. Plant Archives, 17(1):391394.

Ansari, K. 2013. Effect of different collecting time and different medium on rooting of pomegranate cv. Malas Torsh cuttings. Bulletin of Environment, Pharmacology and Life Sciences, 2(12): 164-168.

Rathwa, A.D. (2016). Influence of propagation media on rooting and growth of hardwood and semihardwood cuttings of pomegranate cv. Bhagwa. M.Sc. thesis Department of Fruit Science, Aspee College of
Horticulture and Forestry Navsari Agricultural University navsari.

Sardoei. A. S. (2014) Effect of different media of cuttings on rooting of guava (Psidium guajava). European Journal of Experimental Biology, 4(2):88-92

Haider, A., Khare, N. and Khan, A. 2015.Performance of poplar cuttings with different growth regulators and potting media. Hort Flora Res. Spect., 4(1): 60-63.

Bethke, C. L. 2007. Rice hulls vs perlite and vermiculite as a growing media component. Perlite Institute, Inc

Ors, S. and Anapali, O. 2010. Effect of soil addition on physical properties of perlite based media and strawberry cv. Camarosa plant growth. Scientific Research Essays. 5(22): 3430-3433.

Polat, A.A. and Caliskan, O. 2009. Effect of IBA on rooting cutting in various pomegranate genotypes. Acta Horticulture (ISHS). 818: 187-192.

Smith, P. M. 1976. Minor crops. In N. W., Simmonds: Evolution of crop plants, Longman, New York, USA: 312-313.

\section{How to cite this article:}

Mohammad Ghani, M.K. Sharma and Hukum Khan Habibi. 2019. Effect of Growing Media on Rhizogenesis and Growth of Rooted Stem Cuttings of Pomegranate (Punica granatum) cv. Phule Bhagwa Super. Under Open Field Condition. Int.J.Curr.Microbiol.App.Sci. 8(07): 915923. doi: https://doi.org/10.20546/ijcmas.2019.807.110 